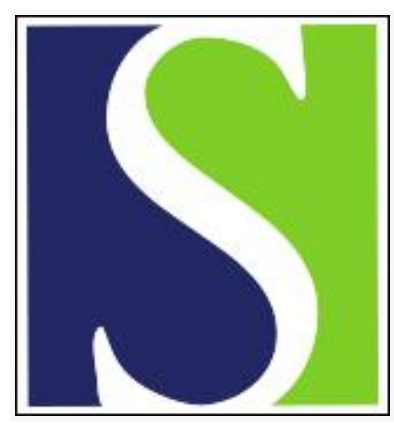

Scand J Work Environ Health 1994;20(2):87-92

https://doi.org/10.5271/sjweh.1416

Issue date: 01 Apr 1994

Prolonged exposure to gunfire noise among professional soldiers.

by Ylikoski ME

Affiliation: Lappeenranta Regional Institute of Occupational Health, Finland.

This article in PubMed: www.ncbi.nlm.nih.gov/pubmed/8079139

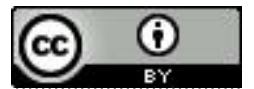




\title{
Prolonged exposure to gunfire noise among professional soldiers
}

\author{
by Matti E Ylikoski, MD'1
}

\begin{abstract}
YLIKOSKI ME. Prolonged exposure to gunfire noise among professional soldiers. Scand $J$ Work Environ Health 1994;20:87-92.
\end{abstract}

\begin{abstract}
OBJEctives - The aim of the study was a retrospective assessment of the exposure of professional soldiers to impulse noise from gunfire.

Methods - A questionnaire on noise exposure and use of hearing protectors was administered to a stratified random sample of 699 army officers (mean age 39.8 years) with an average of 18 years of exposure to shooting noise. For a comparison of the number of shots from different weapons, the peak sound pressure levels of shots were adjusted in relation to one pistol shot according to the equal energy principle. Total exposure time was estimated with the equal energy principle, the number of shots from different weapons, the energy levels of different shots, the effectiveness of hearing protection, and the distance from the noise source being taken into account.

REsults - Rifles, shotguns, and pistols were the predominant exposure sources. Impulse noise exposure averaged 164183 shots from different weapons. After adjustment to the energy level of one pistol shot, the average was 78000 personally fired shots. The total shooting noise exposure averaged 218000 adjusted shots. Translated into exposure to steady noise of $85 \mathrm{~dB}(\mathrm{~A})$ for $40 \mathrm{~h}$ a week, the exposure to noise from personally fired shots equaled an exposure time of 22.0 years and the total exposure averaged 61.0 years. The heaviest exposure occurred during the first $10-15$ years of the men's careers.

Conclusions - Exposure to gunfire noise among professional soldiers is high enough to cause severe hearing deterioration already at early career stages if effective hearing protectors are not worn at all times on shooting occasions.
\end{abstract}

KEY TERMS - equal energy principle, hearing protection, impulse noise, military noise.

Military personnel and conscripts run a very high risk of suffering noise-induced hearing loss as a result of exposure to noise from gunfire and explosions (14). The prevalence of hearing loss appears to be higher for army personnel than for industrial workers exposed to steady noise (5). It has been shown that hearing protectors are not worn regularly on all shooting occasions and that the attenuation of hearing protectors is insufficient against low-frequency noise from large-caliber weapons $(4,6,7)$. This suggestion is rather controversial, however, because recent data indicate that low-frequency noise is relatively less hazardous than could be expected on the basis of the equal energy principle $(8-10)$. On the other hand, there are only a few studies on the qualities and accumulated numbers of different shots fired by men during their mandatory military service or career $(11,12)$. In addition, the estimation of exposure to shooting impulses has been difficult since only few feasible suggestions have been introduced to assess the complex exposure to shooting impulses from weapons of different caliber $(13,14)$.

1 Lappeenranta Regional Institute of Occupational Health, Lappeenranta, Finland, and Department of Otolaryngology, Kuopio University Hospital, Kuopio, Finland.

Reprint requests to: Dr M Ylikoski, Steniuksentie 24 A 7 , FIN-00320 Helsinki, Finland.
Impulse noise appears to have a detrimental effect on hearing after a fairly short period of exposure, and hearing loss increases rapidly during the first few years $(3,11)$. It has been argued that the great variations in the degree of hearing loss from shooting noise are largely attributable to differences in susceptibility to noise and only a minor part of these differences can be explained by exposure time $(1,5$, $9,10)$. To confirm this opinion, careful analyses concerning the number of shots, the peak sound pressure level, and the spectral content of the wave form, the distance from the noise source and the use of hearing protectors are necessary on an individual basis.

Recently, the importance of exposure data analyses has been further accentuated by animal studies which show that the frequency domain, and thus the shooting impulse, is crucial to an understanding of the damage $(3,8,9,15,16)$. The exposure to shooting impulses, in addition to the exposure to steady noise, has been recently studied in a group of forest workers (13). In this study a multivariate model was introduced for estimating exposure to shooting impulses (13). On the other hand, no recent study exists in which a systematic collection of long-term exposure data has been combined with audiometric data to evaluate auditory hazards in a larger population of professional soldiers. Professional soldiers represent a typical population of persons exposed to 
impulse noise with only occasional exposure to steady noise.

This study was undertaken to assess the long-term effects of exposure to gunfire noise on health and work ability. The objective was to collect noise exposure data on randomly selected professional soldiers.

\section{Subjects and methods}

In this questionnaire study a stratified random sample of 786 Finnish army officers was collected from all of the regular army officers included in the personnel files on 1 January 1987. The stratification was performed according to the age distribution of all army officers. Questionnaire data were available for 718 men (rate of return $90.9 \%$ ). Nineteen were excluded because of incomplete data ( 9 cases) or apparent ear disease (10 cases). Thus data from 699 subjects (mean age 39.8 years) were included in the analysis.

Questions were asked separately for each of the commonly used weapons or categories of weapons (military and nonmilitary) for retrospective information on the average number of rounds fired with the relevant weapon on a typical shooting occasion, the average annual number of these typical shooting occasions, and the number of years that the subject had been exposed to noise from the particular weapon before the time of the study. The numbers of individually fired shots and shots heard as an instructor in shooting exercises (including data on the distance between the instructor and the noise source) were reported separately. The total number of individually fired shots and supervised shots was calculated for each weapon.

The questions also covered the use and type of hearing protectors during shooting. In addition, information on exposure to steady noise (industrial and other) and noise during leisure time was requested.

\section{Calculation of total number of shots}

Peak sound pressure levels (peak level) and the forms of pressure wave are known to vary in accordance with the strength of the cartridge and the caliber of the weapon $(11,15)$. The number of shots from each weapon was adjusted with the equal energy principle, the peak level of impulse noise from one pistol shot being used as the reference [ie, 154 (SD 2.6) $\mathrm{dB}](1,3,17)$. The peak levels of different weapons measured in earlier studies were used in the calculation $(7,18-22)$.

\section{Calculation of total exposure time}

The total effective exposure time to shooting impulses was calculated according to the equal energy principle on the basis of earlier data on energy levels of different shots $(19,21-23$, unpublished manuscript) by converting them to 8 -h exposure time according to equations 1 and 2 as presented earlier (23). Equation 1 presents the energy (E) of one impulse, which is

$$
\mathrm{E}=\int_{\mathrm{T}} \mathrm{p}^{2} \cdot \mathrm{dt},
$$

(equation 1)

where $\mathrm{p}=$ peak pressure and $\mathrm{T}=$ period of time. Equation 2 presents the sound exposure level (energy level in decibels) $\left(\mathrm{L}_{\mathrm{E}}\right)$ :

$$
\mathrm{L}_{\mathrm{E}}=10 \log \left(\mathrm{E}_{\mathrm{E}} \mathrm{E}_{\mathrm{o}}\right)
$$

(equation 2)

where $E_{o}=4 \cdot 10^{-10} \mathrm{~Pa}^{2} \cdot \mathrm{s}$ for an integration period of $1 \mathrm{~s}$ and a reference pressure of $20 \mathrm{mPa}$ (according to equation 1).

Before the multiplication with the number of shots fired and instructed, the energy levels in equation 1 were adjusted according to the reported hearing protection. The attenuation of earplug-type hearing protectors was estimated on the basis of earlier studies to be $10 \mathrm{~dB}$ for large-caliber weapons, $15 \mathrm{~dB}$ for assault rifles and pistols, and $20 \mathrm{~dB}$ for leisure-time shooting. The attenuation of earmuffs was estimated to be 5,20 , and $25 \mathrm{~dB}$, respectively $(6,7,10,13$, 17, 23-26). All officers rated their habits of wearing hearing protectors using the following four-grade index: 1 = practically never; $2=$ occasionally; $3=$ frequently; 4 = constantly. The attenuation provided by the hearing protectors was estimated for each subject on the basis of his wearing index and equal energy principle when the index was below 4.0.

The distance between the exposed individual and noise source was taken into account as a sound-level $(\Delta \mathrm{L})$ reducing factor according to the following equation:

$$
\Delta \mathrm{L}=20 \log \left(\mathrm{r} / \mathrm{r}_{\mathrm{o}}\right)
$$

(equation 3)

where $\mathbf{r}=$ distance $(\mathrm{m}), \mathrm{r}_{\mathrm{o}}=$ reference distance $(0.5 \mathrm{~m})$.

In the case of fired shots, the distance was assumed to be the reference distance. Distances from earlier studies were used for shooting and instructing with different weapons (23). The reducing effects of the directionality of sound pressure waves or the air absorption of sound energy were not taken into account.

In the statistical analysis correlations were calculated between variables with the Pearson correlation coefficient, and the statistical significances of the differences were tested with Student's t-test using SAS (Statistical Analysis System) software.

\section{Results}

\section{Shots with different weapons}

Military rifles and pistols were the most frequently used weapons. Cannons (caliber $<75 \mathrm{~mm}$ ) were the most frequent large-caliber weapons used. Table 1 shows the number of shots fired by the officer him- 
self and, in the cases of rifles and bazookas, under his supervision.

In instructing situations, most of the officers were exposed to impulse noise from almost twice as many shots as they typically fired themselves. For bazookas and cannons the exposure data were available only if the distance of the subject was less than $40 \mathrm{~m}$ from the weapon. In the case of cannons, the difference between shooting and instructing was difficult to interpret from the data.

For most of the officers shooting was or had been a hobby. The average number of annual shots fired during leisure time varied between different age groups from 577 (pistol shots by 40 - to 49 -year-olds) to 2601 shots (rifle shots by 30 - to 39 -year-olds).

Leisure-time shooting was the most popular between the ages of 30 and 40 years (on the average 3200 shots annually), and the rifle was the preferred weapon.

\section{Total number of shots}

The total number of shots fired by different weapons by the officer himself, the shots he supervised as an instructor, and the shots fired during leisure time were counted individually for each subject. The mean of the numbers of personally fired shots was 27745 (SD 8714, median 11 128). Five percent of the officers had fired more than 99400 shots during their career, and $1 \%$ had fired more than 440000 shots. The mean of the total number of shots (fired and heard as an instructor) was 164183 (SD 29600 , median 61300 ). In the group comprising $1 \%$ of the men with the highest exposure frequency, the total number of shots averaged 796000 .

\section{Duration of exposure and number of shots}

The largest number of personally fired shots was reported by the oldest officers, who had been exposed to weapon noise for more than 30 years (figure 1).
On the average, the 46 men in the oldest age group had fired 47541 (SD 12 000) shots. With regard to the total number of shots, the exposure peak occurred in the group with exposure for 25-29 years. This group had been exposed, on the average, to 201632 (SD 59 000) shots. The duration of exposure showed a poor linear correlation with the number of personally fired shots [correlation coefficient (r) 0.09 ] and the total number of shots ( $\mathrm{r} 0.14$ ). Table 2 gives the results with regard to the numbers of personally fired shots and the total numbers of shots after extrapolation in relation to the peak level of one pistol shot.

According to equations 1 and 2, the energy of all reported shots corresponded to an equivalent exposure of $85 \mathrm{~dB}(\mathrm{~A})$ to steady noise for 34953 8-h days, which equals 140 years, on the assumption of an exposure to continuous noise for $5 \mathrm{~d}$ a week. The total average exposure time for impulses of shots fired

Table 1. Shots fired with different weapons by the officer himself or under his supervision from the start of shooting activities up to the time of the study (mean duration 17.9 years).

\begin{tabular}{lrrrr}
\hline & $\begin{array}{c}\text { Number of } \\
\text { exposed } \\
\text { subjects }\end{array}$ & \multicolumn{3}{c}{ Number of shots } \\
\cline { 3 - 5 } & 654 & 7168 & 4701 & 2000 \\
& & & & \\
Pistol & 655 & 7256 & 3762 & 2000 \\
Rifle & 568 & 55549 & 24380 & 40000 \\
$\quad \begin{array}{l}\text { Personal shots } \\
\text { Supervised shots }\end{array}$ & 294 & 5676 & 4222 & 800 \\
Machine gun & 122 & 15316 & 6213 & 4000 \\
Other light weapon & 254 & 2816 & 1700 & 600 \\
Mortar & & & & \\
Bazooka (55 mm) & 423 & 999 & 199 & 1000 \\
$\quad$ Personal shots & 354 & 112 & 93 & 20 \\
$\quad$ Supervised shots & & & & \\
Bazooka (95 mm) & 174 & 765 & 351 & 200 \\
$\quad$ Personal shots & 236 & 50 & 160 & 16 \\
$\quad$ Supervised shots & 340 & 5122 & 2518 & 1000 \\
Cannons (<75 mm) & 209 & 3274 & 1867 & 750 \\
Cannons (>75 mm) & 423 & 3326 & 1858 & 1000 \\
Explosives & 85 & 4378 & 1657 & 550 \\
\hline Other explosions & & & & \\
\hline
\end{tabular}

Figure 1. Average numbers of shots in relation to exposure time in years $(\mathrm{N}=699)$

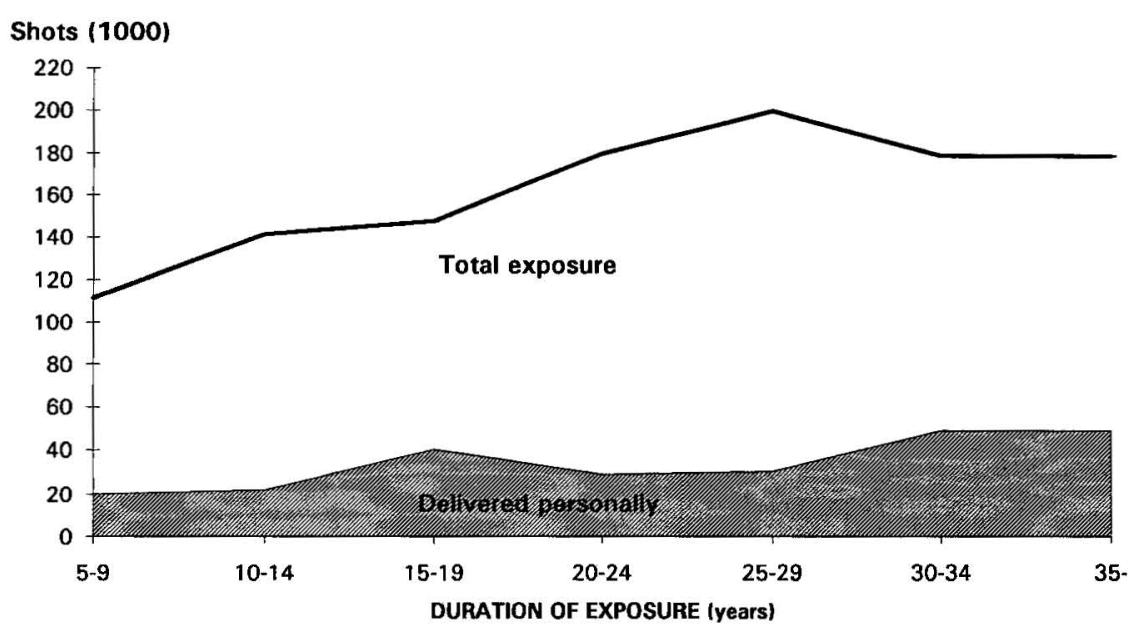


personally equaled 50.3 years of exposure to steady noise.

\section{Hearing protection during shooting}

As seen in figure 2, earplugs and earmuffs were commonly used at the time when the officers began their career (index average 2.95 for earplugs and 3.73 for earmuffs). The use of earplugs appeared to decrease with increasing age (figure 2), while the use of earmuffs varied only slightly between different age groups. Earmuffs were used significantly $(\mathrm{P}<0.05)$ more consistently than earplugs. Of the 110 officers below 30 years of age, $0.9 \%$ had never worn hearing protectors. In the age groups of $30-40$ years and $40-50$ years, the corresponding percentages were 1.2 and 2.1 .

The individual effective hearing protection indices varied from 1 to 4 with an average of 2.8 (SD

Table 2. Mean adjusted numbers of shots distributed according to the age of the army officers. Means are given for personally fired shots and for the total number of shots fired and supervised by the officers. Numbers are adjusted in relation to the noise energy level of one pistol shot ( $154 \mathrm{~dB}, 0.3 \mathrm{~ms})$.

\begin{tabular}{lrrr}
\hline \multirow{2}{*}{$\begin{array}{l}\text { Age } \\
\text { group } \\
\text { (years) }\end{array}$} & $\begin{array}{c}\text { Number } \\
\text { of men }\end{array}$ & \begin{tabular}{c} 
Weighted number of shots \\
\cline { 3 - 4 } personally
\end{tabular} & $\begin{array}{c}\text { Total } \\
\text { (fired and } \\
\text { supervised) }\end{array}$ \\
\hline $25-29$ & 112 & 50540 & 149110 \\
$30-34$ & 85 & 57903 & 178281 \\
$35-39$ & 87 & 81201 & 198193 \\
$40-44$ & 193 & 94211 & 250995 \\
$45-49$ & 157 & 78751 & 252488 \\
$50-54$ & 46 & 90292 & 223439 \\
$55-64$ & 19 & 130478 & 259027 \\
\hline Total & 699 & 78435 & 217836 \\
\hline
\end{tabular}

0.7 , median 3.0 ). For $90 \%$ of the officers the index was higher than 3.7 , and only $1 \%$ had a value below 1.6. Almost constant use of hearing protectors was reported by $5.3 \%$ of the officers, and $50 \%$ had had moderate or fairly good protection. Hearing protection had been inadequate for $10.2 \%$ of the men. Three officers $(0.6 \%)$ had not used any effective hearing protection at all. According to the equal energy principle and the reported use of hearing protectors, hearing protectors had reduced the total exposure by an average of $5.5 \mathrm{~dB}$ per officer.

\section{Effective duration of exposure to shooting noise}

When the attenuation of hearing protectors and the distance from the noise source were taken into account, the adjusted average duration of exposure was expressed in terms of steady noise of $85 \mathrm{~dB}(\mathrm{~A})$ for $8 \mathrm{~h}$ a day for $5 \mathrm{~d}$ a week. This adjusted average duration of exposure was 22.0 (SD 2.6, range 16.227.2) years for personally fired shots and 61.0 (SD 4.4, range 41.5-69.7) years for all of the shots fired and supervised by the officers. Table 3 presents the total exposure time for the different age categories.

\section{Discussion}

To examine the questionnaire data for a possible bias caused by faulty recollection, the total number of reported shots was checked against the official military records of cartridges consumed in relevant garrisons. There was no significant discrepancy between the questionnaire data and the military statistics.

With all types of noise, the adverse effects on hearing are determined by the quality and quantity of the relevant noise. The risk of hearing loss is related to

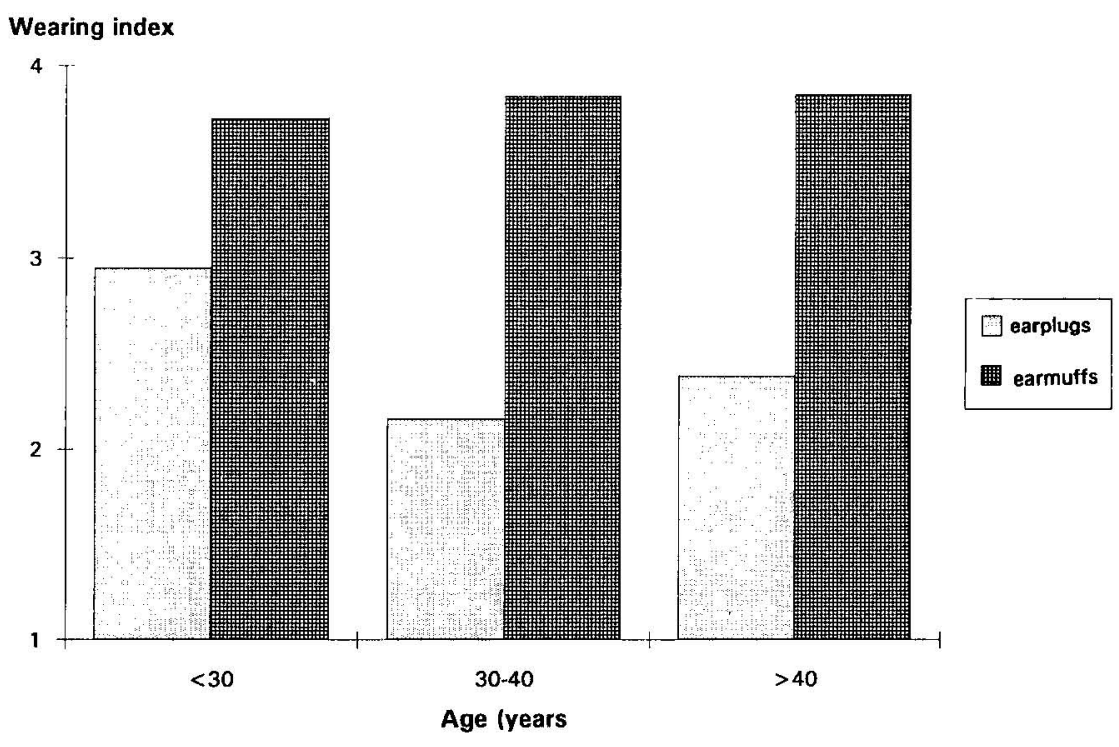

Figure 2. Frequency of wearing ear protectors (earmutfs and ear plugs separately) at different ages. (Wearing index: $1=$ practically never, $2=$ occasionally, $3=$ frequently, $4=$ constantly) 
the total energy of noise (27), and the equal energy principle has been proposed also for the risk assessment of weapon impulses (17). Damage risk criteria proposed for weapon impulses are based on the duration and number of impulses $(13,26)$ and also on the hearing protection employed $(6,23)$.

In the present study the equal energy principle was applied. Consideration was given to the differences noted in the attenuation efficiencies of hearing protectors against high- and low-frequency impulse noise $(7,25)$. Although the equal energy principle is generally accepted as a basis for assessing both sound pressure energy and the risk of hearing loss in the case of steady noise $(13,17)$, inconsistencies still exist in the application of the equal energy principle to impulse noise $(3,10,13,15)$. Recent animal studies have given controversial results with regard to damage caused to the inner ear by impulse noise, and in many studies findings do not support the equal energy principle very strongly $(9$, $10,15,27)$. It has been suggested that the hazard from low-frequency impulses is unexpectedly low compared with the risk associated with higher frequency impulses $(9,15)$. In spite of justified criticism concerning the application of the equal energy principle to impulse noise, the principle was used in the present study to facilitate the comparison with earlier exposure studies $(4,5)$. On the other hand, one recent study has introduced a promising suggestion for calculating the exposure to shooting impulses with a logarithmic summation of the shots (13).

Nevertheless, exposures above the critical level of $140-150 \mathrm{~dB}$ are considered extremely hazardous (9), and the equal energy principle is only applicable, according to the International Organization for Standardization, to values below the 140 -dB peak level (28). In the present study, the equal energy principle was used to estimate total exposure, and the figure arrived at might be an underestimate. However, the army officers almost invariably wore hearing protectors, which attenuate the peak level of shooting noise. Thus, in most cases, the sound level reaching the ear was about $140 \mathrm{~dB}$, which is close to the critical level (9).

Anttonen et al (11) estimated the annual exposure of supervising officers to comprise an average of $30000-70000$ shots with rifle-caliber weapons and $1000-3000$ shots with large-caliber weapons (11). These numbers are higher than in the present study, in which the annual average of shots was below 10000 (164000 in 17.9 years). There were indeed officers in this study who had fired more than two million shots, but they were a minority. Compared, on the other hand, with Kryter's (5) estimate that the mean 8-h effective equivalent level of gun noise during military service or hunting-target shooting or both in an unselected population sample is approximately $89 \mathrm{~dB}$, the exposure data in the present military group is very high.
Table 3. Mean adjusted duration of total exposure of the army officers to impulse noise (translated to corresponding duration of exposure to steady noise of $85 \mathrm{~dB}$ for a $8 \mathrm{~h}$ day for $40 \mathrm{~h}$ a week with the equal energy principle) in relation to the age of the army officers.

\begin{tabular}{lccc}
\hline \multirow{2}{*}{$\begin{array}{l}\text { Age } \\
\text { group } \\
\text { (years) }\end{array}$} & $\begin{array}{c}\text { Number } \\
\text { of men }\end{array}$ & \multicolumn{2}{c}{ Exposure time (years) } \\
\cline { 3 - 4 } & 110 & Mean & SD \\
\hline $25-29$ & 86 & 41.5 & 4.3 \\
$30-34$ & 90 & 49.3 & 4.6 \\
$35-39$ & 190 & 55.3 & 5.2 \\
$40-44$ & 158 & 69.1 & 4.3 \\
$45-49$ & 65 & 69.7 & 5.2 \\
$\geq 50$ & 699 & 66.7 & 6.2 \\
\hline Total & & 61.0 & 4.4 \\
\hline
\end{tabular}

Most of the officers $(90.0 \%)$ in this study had worn hearing protectors during shooting at least with moderate frequency. The officers wore hearing protectors more frequently than, for instance, forest workers according a recent study which showed an $82.0 \%$ use of hearing protectors (13). On the other hand, a Finnish study carried out in 1978 showed that $13.9 \%$ of conscripts failed to wear hearing protectors during shooting exercises (4). Of all the 333 conscripts with verified acute acoustic trauma during 1970$1980,61.3 \%$ reported not having used hearing protectors during their shooting exercises (12).

The poor linear correlation between age and the magnitude of exposure in the present study can be partly explained by the careers of military officers. During the first $10-15$ years, officers are generally exposed in their capacity as supervisors and they also practice shooting themselves. Officers of higher rank tend to have fewer duties which involve shooting.

The results of the present exposure study do not provide any evidence which could justify a change in the current recommendations for the use of effective hearing protectors. They must be worn at all times on shooting occasions. Further studies are also needed for more accurate evaluation of the harmful effects of shooting noise impulses on hearing.

\section{References}

1. Coles RRA, Garinther GR, Hodges DC, Rice CG. Hazardous exposure to impulse noise. J Acoust Soc Am 1968:43:336-43.

2. Salmivalli A. Acoustic trauma in regular army personnel: clinical and audiological study. Acta Otolaryngol Suppl (Stockh) 1967;222:1-85.

3. Price RG. Relative hazard of weapon impulses. J Acoust Soc Am 1983;73:556-66.

4. Riihikangas P, Anttonen H, Hassi J, Sorri M. Hearing loss and impulse noise during military service. Scand Audiol Suppl 1980;12:292-95.

5. Kryter KD. Effects of nosocusis, and industrial and gun noise on hearing of US adults. J Acoust Soc Am 1991;90:3196-201.

6. Pekkarinen JO, Starck JP, Ylikoski JS. Hearing protectors against high level shooting impulses in relation to hearing damage risk criteria. J Acoust Soc Am 1992;91:196-202. 
7. Starck JP, Pekkarinen JO, Aatola S. Attenuation of earmuffs against low frequency noise. J Low Freq Noise Vib 1987;6:167-74.

8. Price GR. Hazard from intense low-frequency acoustic impulses. J Acoust Soc Am 1986;80:1076-86.

9. Price GR, Wansack S. Hazard from an intense midrange impulse. J Acoust Soc Am 1989;86:2185-91.

10. Dancer A, Grateau P, Cabanis A, Barnabe G, Gagnin $G$, Vaillant T, et al. Effectiveness of earplugs in highintensity impulse noise. J Acoust Soc Am 1992;91: $1677-88$.

11. Anttonen H, Sorri M, Hassi J, Riihikangas P. The impulse noise exposure during military service. Scand Audiol Suppl 1980;12:17-24.

12. Ylikoski J. Acute acoustic trauma in Finnish conscripts: etiological factors and characteristics of hearing impairment. Scand Audiol 1989;18:161-5.

13. Pekkarinen J, Iki M, Starck J, Pyykkö I. Hearing loss risk from exposure to shooting impulses in workers exposed to occupational noise. Br J Audiol 1993;27: $175-82$.

14. Lutman ME, Spencer SS. Occupational noise and demographic factors in hearing. Acta Otolaryngol Suppl (Stockh) 1991;476:74-84.

15. Hamernik RP, Ahroon WA, Hsueh KD. The energy spectrum of an impulse: its relation to hearing loss. J Acoust Soc Am 1991;91:197-201.

16. Price GR, Kim HN, Lim DJ, Dunn D. Hazard from weapon impulses: histological and electrophysiological evidence. J Acoust Soc Am 1989;85:1245-54.

17. Martin AM. The equal energy concept applied to impulse noise. In: Henderson D, Hamernik RP, Dosanh DS, Mills JH, ed. Effect of noise on hearing. New York, NY: Raven Press, 1976:421-53.

18. Ylikoski J, Pekkarinen J, Starck J. The efficiency of earmuffs against impulse noise from firearms. Scand Audiol 1987; 16:85-8.

19. Pekkarinen J. Exposure to impulse noise, hearing pro- tection and combined risk factors in the development of sensory neural hearing loss [dissertation]. Kuopio (Finland): University of Kuopio, 1989. (Original reports 4/1989.)

20. Smoorenburg GF, ed. Effects of impulse noise. Brussels: NATO, Research Study Group, 1987. (Document AC/243 (panel 8/RSG.6) D/).)

21. Pääkkönen R. Low-frequency high level noise impulses near weapons and explosions. J Low Freq Noise Vib 1988;7:42-9.

22. Pääkkönen $R$. Noise control on military shooting ranges for rifles. Appl Acoust 1991;32:49-60.

23. Pääkkönen $R$. Low-frequency impulse noise and its attenuation by hearing protectors and other technical means [dissertation]. Tampere (Finland): University of Technology, 1993. (Publication 117/1993.)

24. Nixon CW. Hearing protection devices: ear protectors. In: Haris CM, ed. Handbook of noise control. 2nd edition. New York, NY: McGraw-Hill, 1979:12-3.

25. Liu CC, Pekkarinen JO, Starck JP. Application of the probe microphone method to measure attenuation of hearing protectors against high impulse sound levels. Appl Acoust 1989;27:13-25.

26. Pfander F. Damage risk criteria with and without ear protection for impulse noise with high intensities regarding ear, larynx and lungs. Scand Audiol Suppl $1980 ; 12: 41-6$.

27. Roberto M, Hamernik RP, Salvi RJ, Henderson D, Milone R. Impact noise and equal energy hypothesis. J Acoust Soc Am 1985;77:1514 -20.

28. International Organization for Standardization (ISO). Assessment of occupational noise exposure and for hearing conservation purposes. Geneva: ISO, 1975. (ISO/DIS 1999 Acoustics).

Received for publication:3 June 1993 